\title{
The effects of age-of-acquisition and frequency-of-occurrence in visual word recognition: Further evidence from the Dutch language
}

\author{
Marc Brysbaert \\ Universiteit Gent, Belgium \\ Marielle Lange \\ Université Libre de Bruxelles, Belgium \\ Ilse Van Wijnendaele \\ Katholieke Universiteit Leuven, Belgium
}

\begin{abstract}
It has been claimed that the frequency effect in visual word naming is an artefact of age-of-acquisition: Words are named faster not because they are encountered more often in texts, but because they have been acquired earlier. In a series of experiments using immediate naming, lexical decision, and masked priming, we found that frequency had a clear effect in lexical tasks when age-of-acquisition is controlled for. At the same time, age-ofacquisition was a significant variable in all tasks, whereas imageability had no effect. These results corroborate findings previously reported in English and Dutch.
\end{abstract}

\section{INTRODUCTION}

Most models of reading assume that the ease of word processing is a function of the frequency with which words have been encountered in the past. High frequency words are more easily recognised than low

\footnotetext{
Requests for reprints should be addressed to M. Brysbaert, Department of Experimental Psychology, University of Ghent, Henri Dunantlaan 2, B-9000 Gent, Belgium.

Email: marc.brysbaert@rug.ac.be

The research reported here has been supported by an "Inter-universitary Poles of Attraction" grant (P4/19) from the Department of Science Policy.
} 
frequency words, and this is true in a wide range of word processing tasks. Accounts of the frequency effect usually refer to the fact that the representations of common words in the mental lexicon are more easily accessed than those of less common words (e.g., due to a lower threshold or to an elevated activation level), or that the search strategy in the mental lexicon is frequency based. As for the lexical decision task, it has additionally been claimed that part of the frequency effect may be caused by post-access decision mechanisms (Chumbley \& Balota, 1984) or by a familiarity check (Besner \& McCann, 1987).

Morrison and Ellis (1995), however, published a paper that seriously questioned the primary status of frequency-of-occurrence in visual word recognition. On the basis of a review of the literature and a series of new experiments, they concluded that frequency effects in word processing are largely an artefact of age-of-acquisition (AoA); that is, the age at which words were learned first. In particular, Morrison and Ellis (1995) claimed that there is no genuine frequency effect in printed word naming (a relatively pure lexical access task) if AoA is controlled for.

The empirical evidence of Morrison and Ellis (1995) was based on two lists of 48 words that were either matched on frequency or on AoA. The frequency measures were based on Kucera and Francis; the AoA measures on student estimates collected by Gilhooly and Logie (1980). In two replications, Morrison and Ellis showed that frequency had no effect on word naming if AoA was controlled for, whereas AoA had a reliable effect of $30 \mathrm{msec}$ when frequency was controlled for. To make sure that the effect of AoA was due to lexical access and not to speech output processes, Morrison and Ellis presented the same stimuli in a delayed naming task. In this task, neither frequency nor AoA had a reliable effect.

In two final experiments, Morrison and Ellis (1995) looked at the effects of word frequency and AoA on the decision latencies in a lexical decision task. This time, both variables had a significant impact. The frequency effect amounted to $54 \mathrm{msec}$, the AoA effect to $66 \mathrm{msec}$. Morrison and Ellis attributed the frequency effect in the lexical decision task to the involvement of semantic representations in word/non-word decisions, or to the involvement of a post-access familiarity check.

Morrison and Ellis's findings have provoked a lot of interest, due to their claim that frequency may not be a critical factor in word recognition. Ever since the seminal work of Howes and Solomon (1951), frequency-of-occurrence has played a dominant role in the literature of word processing, and models of word processing have been evaluated on the basis of how well they explain the frequency effect (Monsell, 1991).

Two main criticisms have been expressed against Morrison and Ellis's findings. The first is that retrospective AoA ratings obtained from a small 
sample of students may not be a good AoA measure. This criticism has since been addressed by Morrison and colleagues, who first showed that student ratings correlate highly with real AoA measures, obtained by asking children of different ages to name pictured objects (Morrison, Chappell, \& Ellis, 1997); and second, that adult object-naming speed is as well predicted by real AoA measures as by student ratings (Ellis \& Morrison, 1998).

The second criticism has been that Morrison and Ellis underestimated the role of word frequency in lexical tasks. Brysbaert (1996) reported a word frequency effect on top of an AoA effect in word naming. He asked primary school children to name 204 Dutch three- and four-letter words, that had been selected so that AoA did not correlate with either the frequency of the words or the length of the words. Using these stimuli, Brysbaert found independent effects of word frequency, word length, and AoA. Shortly afterwards, Gerhand and Barry (1998) failed to replicate Morrison and Ellis's naming data, even when they used the same stimulus set. In two successive replications, they obtained an average frequency effect of $19 \mathrm{msec}$, and an average AoA effect of $32 \mathrm{msec}$. Interestingly, Gerhand and Barry's naming data were considerably faster (478-563 msec) than Morrison and Ellis's (601-647 msec). Furthermore, Gerhand and Barry obtained the same findings with another set of English words, for which frequency and AoA were orthogonally manipulated. In this study, the frequency effect amounted to $22 \mathrm{msec}$ and the AoA effect to $14 \mathrm{msec}$. There was no evidence for an interaction between both factors, leading Gerhand and Barry to conclude that frequency and AoA have an influence at different stages of word processing. Because AoA, unlike frequency, had an effect on the articulation times of words, Gerhand and Barry hypothesised that AoA affects the production of lexical phonology, whereas word frequency affects the visual recognition of words.

So, both the Dutch and the English findings seem to converge on independent effects of frequency and AoA in visual word recognition. However, Brysbaert's (1996) results may be sub-optimal to draw firm conclusions for the Dutch language. First, unlike Morrison and Ellis, and Gerhand and Barry, Brysbaert worked with primary school children. Second, he presented only an immediate naming task. He had no data on delayed naming nor on lexical decision. The delayed naming task is usually added to the immediate naming task, in order to ensure that any effect found in immediate naming is due to the recognition of the visual word or the retrieval of the spoken word form, but not to the process of articulating the word. Lexical decision is another task widely used to investigate word recognition processes, and data of this task are usually combined with those of naming to see how well the findings converge. 
Because of these shortcomings in Brysbaert (1996), we decided to replicate Morrison and Ellis's basic pattern of results (effects of AoA and frequency for immediate naming, delayed naming, and lexical decision). In addition, we wanted to make sure that the AoA effect was not a disguised imageability effect. AoA is highly correlated with word imageability ( $r=-.55$, according to Morrison et al., 1997) and some authors have argued that imageability may be a significant variable in visual word processing (Strain, Patterson, \& Seidenberg, 1995). So, in principle AoA may have been confounded with imageability. This seems unlikely for the English language, as Coltheart, Laxon, and Keating (1988) showed that the AoA effect on word naming remains significant when imageability is controlled for, whereas imageability has no effect when AoA is controlled for. However, we wanted to be sure of the origin of any AoA effect in Dutch. Finally, we looked at the effects of AoA and frequency in another paradigm (masked neighbour priming) that has been claimed to tap into the early stages of visual word processing.

\section{EXPERIMENTS $1 \mathrm{a}-\mathrm{c}$}

Our first series of experiments was an exact replication of Morrison and Ellis's (1995) Experiments 3-6. It included an immediate word naming task, a delayed naming task, and a lexical decision experiment. Three pairs of word lists were compiled: The first pair differed on AoA and was matched for frequency and imageability, the second pair differed on frequency and was matched for AoA and imageability, the third pair differed on imageability and was matched for AoA and frequency.

\section{Method}

Participants. Participants were 60 first-year students of psychology of the University of Leuven (20 per experiment). They received course credits for their participation.

Materials. There were six stimulus lists of 24 four- and five-letter words each (see Appendix 1 for details). For each word we had three measures: AoA, frequency, and imageability (IMA). The AoA measures were based on teachers' ratings collected by Kohnstamm, Schaerlaekens, de Vries, Akkerhuis, and Froonincksx (1981). Kohnstamm et al. asked a representative sample of teachers to indicate for each of 6785 Dutch words whether a 6-year-old should understand it (i.e., passive knowledge). In particular, for the Dutch-speaking part of Belgium, 40 teachers of the last year of Kindergarten and 41 teachers of the first year of primary 
school independently marked which words children should know when they move from kindergarten to primary school (teachers came from all over the region). The same AoAT measure (i.e., AoA based on teachers' judgements) was used by Brysbaert (1996). The frequency measures were based on the Celex database (Baayen, Piepenbrock, \& van Rijn, 1993), which lists written word frequencies based on a total of $42,380,000$ counts (the raw values were used in order not to have negative logarithms for values less than 43; the log values had base 10). The IMA values, finally, were taken from van Loon-Vervoorn (1985) who had all words of the Kohnstamm et al. (1981) list rated on a 7-point scale for imageability.

The first two lists differed on AoAT ( $8 \%$ vs 93\%, meaning that for the late acquired words, only $8 \%$ of the teachers indicated that these words should be known by a 6-year-old, whereas for the early acquired words, $93 \%$ of the teachers expected their pupils to know them). The lists were matched for frequency and as much as possible for IMA. Due to the high correlation between AoA and IMA, it was impossible to create a pair of stimulus lists that at the same time differed strongly on AoA and was perfectly matched for IMA. Therefore, we used a two-step procedure: We first constructed AoA lists controlled for frequency and as good as possible for IMA, and we then constructed two additional lists that differed as much as possible on IMA and were controlled for frequency and AoA (see Appendix 1). If IMA is more important than AoA, we should find a larger difference between the lists in which IMA was manipulated than between the lists in which AoA was manipulated. List 3 and list 4 differed on $\log ($ freq) (1.7 vs 4.0) and were matched for AoA and IMA. Finally, as mentioned earlier, the last two lists differed on IMA (2.9 vs 6.3) and were matched for AoA and frequency. It may be remarked that due to our selection procedure, we gave priority to AoA over IMA, because the difference in AoA was maximised at the expense of IMA. If we had given priority to IMA over AoA, we would have ended with IMA lists that differed more from one another and AoA lists that were less divergent. This allows us to draw firm conclusions on whether AoA is an artefact of IMA, but less on whether IMA by itself is a significant factor in visual word recognition.

All words were different, making a total of $6 \times 24=144$. They are listed in Appendix 1, together with their first English translation in the Dutch-English dictionary "Van Dale Handwoordenboek NederlandsEngels".

Procedure. Participants were tested one at a time in a quiet room. They were given written instructions on the computer screen. The procedure used by Morrison and Ellis (1995) was adopted here. In the immediate naming condition, instructions were to name the words aloud as 
quickly and accurately as possible. A trial started with a blank screen for $1 \mathrm{sec}$, after which two vertically aligned lines appeared at the centre of the screen. The participants were asked to look at the gap between the lines; $500 \mathrm{msec}$ after the appearance of the lines, a word was presented horizontally in such a way that the second letter was situated in the gap between the lines. Previous research has indicated that the second letter is the optimal viewing position for naming short Dutch words (Brysbaert, 1994). Words were presented in lower case and remained visible until the participant reacted or after $770 \mathrm{msec}$ had elapsed. We encouraged participants to respond as quickly as possible, but we also told them that it was acceptable to respond even after the word had disappeared from the screen. Reaction times were measured with a voice key connected to the game port and recorded to the nearest millisecond using software routines published by Bovens and Brysbaert (1990). The correctness of the response was encoded on-line by the experimenter who used three keys of the computer keyboard (correct/incorrect/correct but bad time registration). The next trial started immediately after the experimenter typed in the response code. The 144 items of the six lists were presented at random in a single block, preceded by 20 practice trials. Each participant got a different permutation of all stimuli.

The delayed naming condition was based on the same 144 words. The procedure was also the same, except for one change. The participants were asked not to pronounce the word immediately, but to wait until the word disappeared and two square brackets were shown in the centre of the screen (surrounding the gap between the two vertical fixation lines). In order to prevent anticipatory reactions, there was a random time interval ranging from 100 to $200 \mathrm{msec}$ between the disappearance of the word (which was presented for $770 \mathrm{msec}$ ) and the appearance of the square brackets. Reaction times were again measured with a voice key connected to the game port and recorded to the nearest millisecond.

For the lexical decision condition, legal pseudowords were created by changing one letter of the stimulus words. Vowels were replaced by vowels and consonants by consonants. Care was taken to ensure that no orthographic or phonological rules were violated, and that the non-words were not in an obvious way related to the words (most four- and fiveletter non-words can have many word neighbours by changing one letter). Participants were given written instructions on the computer screen explaining that letter strings would appear on the screen and that their task was to respond "word" or "non-word" by pressing on the left or the right response key (counterbalanced over participants) as quickly and accurately as possible. The instructions were followed by a block of 20 practice trials and the experimental block. Stimulus presentation was the same as in the previous conditions, except that the stimulus remained on 
the screen until the participant reacted. Reaction times and errors were recorded with two response buttons connected to the game port. The stimuli were presented in a different random order for each participant.

\section{Results}

Response times (RTs) shorter than than $100 \mathrm{msec}$ and longer than 1500 msec were discarded from the analyses. Together with the bad time registrations indicated on-line by the experimenter, this resulted in a loss of $1 \%$ of the data in the immediate naming task, $5 \%$ in the delayed naming task, and $0.5 \%$ in the lexical decision task.

Table 1 lists the RTs for the three different experiments as a function of AoA, frequency, and IMA. In the immediate naming experiment, there was a significant effect of frequency $[F 1(1,19)=17.2, M S e=86, p<.01$; $F 2(1,46)=3.7, M S e=465, p<.07]$, an effect of AoA over participants $[F 1(1,19)=8.1, M S e=153, p<.02]$ but not over materials $[F 2(1,46)=2.6$, $M S e=522, p>.10]$, and no effect of IMA $[F 1(1,19)<1, M S e=132$; $F 2(1,46)<1, M S e=762]$. In the delayed naming experiment, none of the effects reached significance [AoA: $F 1(1,19)=1.2, \quad M S e=354 ; F 2(1$, 46)<1; $M S e=946$; frequency: $F 1(1,19)<1, M S e=596 ; F 2(1,46)<1$, $M S e=573$; IMA: $F 1(1,19)<1, M S e=645 ; F 2(1,46)<1, M S e=1011]$. Finally, in the lexical decision experiment, there was a significant effect of AoA $[F 1(1,19)=29.9, M S e=89.2, p<.01 ; F 2(1,46)=10.2, M S e=4752$,

\section{TABLE 1}

Reaction Latencies in Milliseconds and Percentage of Errors of Experiments $1 \mathrm{a}-\mathrm{c}$ as a Function of AoA, Word Frequency, and Imageability

Immediate naming

AoA

Frequency

IMA

Delayed naming

AOA

Frequency

IMA

Lexical decision

AOA
487

478

485 
$p<.01]$, frequency $[F 1(1,19)=54.3, M S e=1334, p<.01 ; F 2(1,46)=24.5$, $M S e=5259, p<.01]$, but not of IMA $[F 1(1,19)<1, M S e=479 ; F 2(1$, $46)<1, M S e=5214]$. ANOVAs on the percentage of errors in the lexical decision task also yielded significance for AoA $[F 1(1,19)=16.7$, $M S e=53, p<.01 ; F 2(1,46)=6.8, M S e=106, p<.02]$, frequency $[F 1(1$, $19)=26.4, M S e=49, p<.01 ; F 2(1,46)=11.0, M S e=95, p<.01]$, but not for IMA $[F 1(1,19)=3.3, M S e=25, p<.10 ; F 2(1,46)=1 ; M S e=74]$.

In order to more fully exploit the power of our design, we ran a multiple regression analysis on the immediate naming times of all 144 stimulus words. The predictor variables were AoA, frequency, IMA, and the average RT for each word in the delayed naming experiment. The latter variable was included because although there were no significant effects in the delayed naming task, differences were in the expected direction. Therefore, to ensure that we obtained real effects of AoA and frequency, over and above differences in word articulation times, we added the naming times of the delayed naming task as an additional predictor variable. The regression analysis was the one recommended by Lorch and Myers (1990) for repeated measures designs and consisted of first calculating the regression weights for each participant separately, and then running a group $t$-test to see whether the mean group values differed significantly from zero. This analysis enables generalisation across stimuli and participants. The resulting regression equation was

$$
\mathrm{RT}_{\text {imm nam }}=393-0.13 \mathrm{AoA}-6.1 \log (\text { freq })+1.4 \mathrm{IMA}+0.34 \mathrm{RT}_{\text {del.nam }}
$$

The regression weights of $\mathrm{AoA}, \log ($ freq $)$, and $\mathrm{RT}_{\text {del.nam }}$ were significant [respectively $t=-2.6, d f=19, \mathrm{SD}=0.23, p<.05 ; t=-6.1, d f=19, \mathrm{SD}=4.25$, $p<.01 ; t=+5.1, d f=19, \mathrm{SD}=0.30, p<.01]$. The regression weight of IMA was not $[t=+1.5, d f=4.23, p>.20]$.

\section{Discussion}

Main findings of Experiments 1a-c were: (a) both frequency-of-occurrence and age-of-acquisition have an effect on naming latency in Dutch, (b) they also affect response latencies in a lexical decision task, and (c) the effect of AoA is not an artefact of word imageability (neither in the naming tasks nor in the lexical decision task).

The first finding is important, because it corroborates Brysbaert's (1996) and Gerhand and Barry's (1998) claim that word frequency effects in oral reading are not merely AoA effects in disguise. It may be remarked, however, that the effects of AoA and frequency in Dutch (11 and $12 \mathrm{msec}$ ) are smaller than the effects usually reported in English (see 
the Introduction). A similar observation has been made by de Groot (1989, Exp. 6, who reported a frequency effect of $19 \mathrm{msec}$ in Dutch naming) and may have to do with the fact that the grapheme-phoneme correspondences are more transparent in Dutch than in English (see Van den Bosch, Content, Daelemans, \& De Gelder, 1994, for a quantitative estimate of the orthographical depth of both languages). The transparency of the grapheme-phoneme correspondences is known to be a critical factor in the magnitude of the frequency effect in word naming, and has been attributed to the greater reliance on non-lexical grapheme-phoneme conversions in languages with a transparent orthography (Frost, Katz, \& Bentin, 1987). In contrast, the AoA and frequency effects in the lexical decision task are of the same magnitude as those reported in English. This too agrees with the existing empirical evidence (Frost et al., 1987).

The finding that the AoA effect is not an artefact of word imageability, confirms Coltheart et al. (1988), and the absence of a genuine main effect of IMA indicates that Strain et al. (1995) may have mistakenly interpreted an AoA effect as an imageability effect. If Morrison and Ellis (1995) are correct in interpreting the AoA effect as a lexical effect, this suggests that Strain et al.'s evidence for semantic mediation in English word naming may not be valid. It should be kept in mind, however, that our IMA manipulation was not the strongest possible (the low list had an average score of 2.9/7, against an average score of $6.3 / 7$ for the high list). So, the difference may not have been large enough to reveal an effect of IMA.

\section{EXPERIMENT 2}

In the previous series of experiments we have shown that both frequencyof-occurrence and AoA affect word processing in Dutch (see also Brysbaert, 1996). Unfortunately, it is hard to maintain that the naming task is a pure lexical task, as assumed by Morrison and Ellis. The smaller AoA and frequency effects in Dutch than in English seem to indicate that Dutch readers rely more on non-lexical strategies when naming printed words (Frost et al., 1987). Furthermore, Gerhand and Barry (1998) argue that word naming not only involves activation of a visual entry at the input side but also retrieval and execution of a phonological representation at the output side, making it impossible to establish whether AoA affects the visual recognition or the retrieval of the phonological representation.

In recent years, researchers have increasingly turned to the masked priming paradigm to investigate early processing stages of word recognition. For instance, Perfetti and colleagues (e.g., Perfetti \& Bell, 1991) used masked priming with pseudohomophones to investigate the role of 
pre-lexical phonological coding in visual word recognition. Similarly, Segui and Grainger (1990) used masked priming with orthographic neighbours to examine the dynamics of lexical activation. Following the idea of McClelland and Rumelhart (1981) that activation of a lexical word representation not only involves excitation from the letter nodes but also inhibition from resembling word representations, Segui and Grainger hypothesised that target word recognition would be slowed down if the target was preceded by a briefly presented orthographic neighbour (this is a word that differs from the target word by one single letter) than when it was preceded by an unrelated control prime. Using forward masking and a $57 \mathrm{msec}$ prime exposure duration (so that the prime stimuli were barely visible), Segui and Grainger reported the expected inhibitory effect for high frequency neighbours and low frequency target words (e.g., blue-BLUR), but not for low frequency primes and high frequency targets (e.g., blur-BLUE). This finding has since been replicated several times (e.g., Bijeljac, Biardeau, \& Grainger, 1997; Drews \& Zwitserlood, 1995). The fact that only high frequency neighbours inhibit low frequency targets, has been explained by assuming that the inhibition depends on the activation level of the lexical representation, which is a function of the printed frequency of the word.

If word frequency affects the visual recognition of words, irrespective of AoA, then we should be able to replicate Segui and Grainger with high frequency primes and low frequency targets, that are matched on AoA. In the same vein, if AoA has an effect on the early stages of visual word recognition, we may be able to find an inhibitory effect of an early acquired prime word on a late acquired neighbour target that is matched for frequency. This is what we investigated in Experiment 2.

\section{Method}

Participants. Participants were 32 undergraduate students of psychology from the University of Leuven. They received course credits for participation.

Stimulus materials. Two lists of 24 stimuli were constructed. The first list included late acquired target words (AoATs of less than 20\%, see Appendix 2 for details) and their early acquired orthographic neighbours plus unrelated controls. The stimuli of the three categories were matched on frequency. A problem with the construction of this list was that we had too few late acquired words with an early acquired neighbour in the Kohnstamm et al. (1981) list. Therefore, we had to include target words that were not in the list because the Kohnstamm research team had previously thought these words would not be known by 6 -years-olds 
(Schaerlaekens, personal communication). The second list consisted of low frequency target words and their high frequency neighbours plus unrelated controls that were matched on AoA. As IMA did not have an effect in Experiments $1 \mathrm{a}-\mathrm{c}$, this variable was no longer included in the stimulus selection, also because it was impossible to find stimuli that in addition would be perfectly matched on IMA. For half of the participants, the odd target words of the lists were presented with their neighbour and the even words with the unrelated control. For the other half of the participants, the combination was reversed.

Procedure. The procedure followed the one outlined by Grainger and colleagues. Stimuli were presented in isolation at the centre of an IBMcompatible computer screen with a $70 \mathrm{~Hz}$ refresh rate. Stimuli appeared as white letters on a dark background. Primes were presented in lower case letters and targets in upper case letters in order to minimise physical overlap in the orthographically related pairs. The masked prime procedure was combined with a lexical decision task. Each trial started with the presentation of a forward mask, consisting of a row of five hashmarks (\#) for $500 \mathrm{msec}$, followed immediately by the prime for $57 \mathrm{msec}$ and the target stimulus, both at the same screen location as the forward mask. The target remained on the screen until participants responded. In addition to the word trials, there were 48 non-word trials in which target non-words had been constructed on the same basis as the word stimuli (i.e., a parallel list of word stimuli had been made first and then the word targets were converted into legal pseudowords by changing one letter, so that we had non-words preceded by early acquired or high frequency neighbour words, and non-words preceded by early acquired or high frequency unrelated control words). All participants got a different randomisation of the stimuli. They were told to make a word/non-word decision to the stimuli presented in upper case letters. They were instructed to expect only Dutch words. The existence of a prime stimulus was not mentioned. Participants reported their decision by pressing on the right or the left response button (which were connected to the game port). The responding hand for the word and the non-word trials was counterbalanced across subjects. Interstimulus interval was $1 \mathrm{sec}$. Before the test block, there were 20 practice trials.

\section{Results}

Table 2 lists the results as a function of stimulus list and prime-target relationship. Because both groups of participants did not react equally fast, participant group was included as a between-participants variable in the RT analyses, giving rise to a split-plot design. In the ANOVAs of 
TABLE 2

Lexical Decision Times and Percentage of Errors in the Masked Priming Experiment (Experiment 2) as a Function of the Nature of the Prime and Whether AOA was Manipulated or Word Frequency

$R T$

(msec)
Errors

$(\%)$

Neighbours Unrelated Differences Neighbours Unrelated Differences

\begin{tabular}{lllrrrr}
\hline AoA & 673 & 662 & 11 & 21 & 11 & 10 \\
Frequency & 641 & 616 & 25 & 8 & 6 & 2 \\
Non-word & 697 & 705 & -8 & 6 & 7 & -1 \\
\hline
\end{tabular}

RT, there was no effect of the prime-target relation when AoA was manipulated $[F 1(1,30)<1, M S e=2236 ; F 2(1,22)<1, M S e=2474]$, but there was a significant effect when frequency was manipulated $[F 1(1$, $30)=5.9, M S e=1786, p<.03 ; F 2(1,22)=5.6, M S e=1470, p<.03]$. RTs to non-words did not differ reliably as a function of prime-target relationship in the analysis over participants $[F 1(1,30)<1, M S e=932]$, although there was a difference in the analysis over stimuli $[F 2(1,46)=5.4$, $M S e=1478, p<.05]$.

The analyses on percentage of error yielded a different pattern of results because there was a significant effect of prime-target relation in the AoA list $[F 1(1,31)=15.3, M S e=93, p<.01 ; F 2(1,23)=7.1, M S e=144, p<.02]$, but not in the frequency list $[F 1(1,31)<1, M S e=63 ; F 2(1,23)<1$, $M S e=32]$. Reactions to non-words did not differ as a function of the prime type $[F 1(1,31)<1, M S e=31 ; F 2(1,23)<1, M S e=40]$.

\section{Discussion}

Using a different paradigm, we again obtained independent effects of AoA and frequency-of-occurrence on visual word processing. As the masked priming paradigm with orthographic neighbours is believed to tap into the lexical input system, we have found further evidence against Morrison and Ellis's claim that the frequency effect in visual word recognition is an artefact of AoA. On the other hand, the significant effect of AoA suggests that AoA may indeed be another organising factor of the visual word recognition system, contrary to what Gerhand and Barry (1998) argued. Slightly worrying is the fact that the frequency effect in the masked priming procedure was found for the RT data only, whereas the AoA effect was largely restricted to the percentage of errors. 


\section{GENERAL DISCUSSION}

The provocative study reported by Morrison and Ellis (1995) suggested that many frequency effects in visual word recognition were an artefact of the age at which the words had been acquired, a variable that is highly correlated with word frequency. If true, this would not only imply that the origin of processing differences between words has been misunderstood, but would also cause difficulties for a whole category of word recognition models, as the AoA effect is not easily explained within the framework of connectionist learning models based on back propagation (Morrison \& Ellis, 1995).

Further research has indicated, however, that Morrison and Ellis underestimated the importance of word frequency in word naming (Brysbaert, 1996; Gerhand \& Barry, 1998; the present studies). Word frequency has an impact on visual word recognition, that cannot be reduced to a disguised AoA effect. This is true for word naming, lexical decision, and masked priming with orthographic neighbours. On the other hand, Morrison and Ellis were right when they pointed to the unjustified neglect of AoA as a significant variable in all these tasks (although a combined frequency and AoA effect is probably not very detrimental to most existing models of visual word recognition).

Given that AoA has a reliable effect in many visual word recognition tasks, it may be worthwhile to speculate a moment where the effect originates from. To do so, we will use the traditional distinction between visual input lexicon, semantic system, and phonological output lexicon, even though these concepts are no longer shared by all researchers, as they do not seem necessary to simulate important effects with connectionist models (Seidenberg \& McClelland, 1989).

Morrison and Ellis (1995) seemed to favour the phonological output lexicon as the origin of the AoA effect, when they wrote (pp. 128-129):

If all AOA effects are to be ascribed to differences between early- and lateacquired words in the ease of phonological retrieval, then to explain AOA effects in lexical decision we must argue that phonological representations are consulted by participants in the lexical decision task before making yes responses to words.... We would persist for now with our contention that the AOA effect in lexical decision reflects the involvement of lexically derived phonology in the decision-making process, with the phonological representations of early-acquired words being accessed faster than those of late-acquired words.

A similar position was taken by Gerhand and Barry (1998) who wrote (p. 268): "Of course, it is quite plausible for both AoA and frequency to 
have effects at different stages of processing, and we worked within a theoretical framework that proposes that frequency affects the process of word recognition, whereas AoA affects the process of phonological retrieval, execution, or both." Gerhand and Barry's position was corroborated by the findings (a) that the effects of frequency and AoA did not interact, and (b) that AoA, but not frequency, was a significant factor in an articulation task in which participants had to repeat the pronunciation of a word 10 times as fast as possible. This position would require that phonological retrieval is also involved in Segui and Grainger's (1990) masked priming procedure. Otherwise, the AoA effect in Experiment 2 indicates that AoA has an effect on the visual input lexicon as well, in addition to word frequency (see e.g., Forster (1992) for a visual word recognition model that would predict such an effect).

Another possibility is that AoA originates from the semantic system. It may not be inconceivable that the organisation of the semantic system parallels the initial learning order, with the meaning of later acquired concepts being built on the meaning of earlier acquired concepts. This would imply that AoA is highly correlated with other variables that have hitherto been considered as primary semantic characteristics, and that AoA has a significant effect in tasks that draw on semantic information. As for the former, it may be interesting to note that the correlation between AoA and semantic variables is usually higher than the correlation between AoA and frequency. Rubin (1980) reported a correlation of -.40 between AoA and frequency, together with a correlation of -.59 between AoA and IMA. The same was true for Whaley (1978) who reported correlations of respectively -.52 and -.69 . In both studies, factor analysis indicated that AoA loaded most on a semantic factor that included variables such as imagery, concreteness, and number of meanings. Morrison et al. (1997) obtained a correlation of -.47 between their real AoA measure and the logarithm of the Cobuild frequency, compared to a correlation of -.55 between AoA and imageability. On the other hand, the evidence for an AoA effect on semantic tasks is mixed. Van Loon-Vervoorn (1989) obtained a significant effect of AoA and imageability on the reaction latencies in a discrete word association task, in which participants were asked to say the first word that came to their mind when they saw a stimulus word (an effect we replicated in our laboratory with the stimuli from Appendix 1). The AoA effect is also particularly strong in object naming, which requires not only the correct name to be produced but also semantic activation to connect the pictorial input with the correct name (e.g., Snodgrass, 1984; Theios \& Amrhein, 1989). On the other hand, Morrison, Ellis, and Quinlan (1992) failed to obtain an AoA effect in a semantic classification task in which participants were asked to classify objects as naturally occurring (e.g., apple) or 
artificial (e.g., anchor). So, it seems that more work is needed to investigate whether AoA could indeed be an organisational principle of the semantic system, and what effects this would have on visual word recognition.

In summary, the present findings indicate that Morrison and Ellis were right when they argued that AoA should be controlled in visual word recognition experiments. This is not only true for English but also for Dutch. However, it also becomes clear that the frequency effect is not an artefact of AoA, and that more work is needed to pin down the word processing stages in which AoA plays a role.

Manuscript received June 1997

Revised manuscript received February 1999

\section{REFERENCES}

Baayen, R.H., Piepenbrock, R., \& van Rijn, H. (1993). The CELEX lexical database [CDROM]. Linguistic Data Consortium, University of Pennsylvania, Philadelphia.

Besner, D., \& McCann, R.S. (1987). Word frequency and pattern distortion in visual word identification and production: An examination of four classes of models. In M. Coltheart (Ed.), Attention and performance XII: The psychology of reading (pp. 201-219). Hove, UK: Lawrence Erlbaum Associates Ltd.

Bijeljac, R., Biardeau, A., \& Grainger, J. (1997). Masked orthographic priming in bilingual word recognition. Memory and Cognition, 25, 447-457.

Bovens, N., \& Brysbaert, M. (1990). IBM PC/XT/AT and PS/2 Turbo Pascal timing with extended resolution. Behavior Research Methods, Instruments, and Computers, 22, 332334.

Brysbaert, M. (1994). Interhemispheric transfer and the processing of foveally presented stimuli. Behavioural Brain Research, 64, 151-161.

Brysbaert, M. (1996). Word frequency affects naming latency in Dutch with age of acquisition controlled. European Journal of Cognitive Psychology, 8, 185-193.

Chumbley, J.I., \& Balota, D.A. (1984). A word's meaning affects the decision in lexical decision. Memory and Cognition, 12, 590-606.

Coltheart, V., Laxon, V.J., \& Keating, C. (1988). Effects of word imageability and age of acquisition on children's reading. British Journal of Psychology, 75, 1-12.

de Groot, A.M.B. (1989). Representational aspects of word imageability and word frequency as assessed through word association. Journal of Experimental Psychology: Learning, Memory, and Cognition, 15, 824-845.

Drews, E., \& Zwitserlood, P. (1995). Effects of morphological and orthographic similarity in visual word recognition. Journal of Experimental Psychology: Human Perception and Performance, 21, 1098-1116.

Ellis, A.W., \& Morrison, C.M. (1998). Real age-of-acquisition effects in lexical retrieval. Journal of Experimental Psychology: Learning, Memory, and Cognition, 24, 515-523.

Forster, K.I. (1992). Memory-addressing mechanisms and lexical access. In R. Frost \& L. Katz (Eds.), Orthography, phonology, morphology, and meaning (pp. 413-434). Amsterdam: Elsevier.

Frost, R., Katz, L., \& Bentin, S. (1987). Strategies for visual word recognition and ortho- 
graphical depth: A multilingual comparison. Journal of Experimental Psychology: Human Perception and Performance, 13, 104-115.

Gerhand, S., \& Barry, C. (1998). Word frequency effects in oral reading are not merely ageof-acquisition effects in disguise. Journal of Experimental Psychology: Learning, Memory, and Cognition, 24, 267-283.

Gilhooly, K.J., \& Logie, R.H. (1980). Age-of-acquisition, imagery, concreteness, familiarity, and ambiguity measures of 1944 words. Behavior Research Methods and Instrumentation, 12, 395-427.

Howes, D.H., \& Solomon, R.L. (1951). Visual duration thresholds as a function of word probability. Journal of Experimental Psychology, 41, 401-410.

Kohnstamm, G.A., Schaerlaekens, A.M., de Vries, A.K., Akkerhuis, G.W., \& Froonincksx, M. (1981). Nieuwe streeflijst woordenschat. Lisse, The Netherlands: Swets \& Zeitlinger.

Lorch, R.F., Jr., \& Myers, J. (1990). Regression analyses of repeated measures data in cognitive research. Journal of Experimental Psychology: Learning, Memory, and Cognition, 16, 149-157.

McClelland, J.L., \& Rumelhart, D.E. (1981). An interactive activation model of context effects in letter perception: Pt. I. An account of basic findings. Psychological Review, 88, 375-407.

Monsell, S. (1991). The nature and locus of word frequency effects in reading. In D. Besner \& G.W. Humphreys (Eds.), Basic processes in reading: Visual word recognition (pp. 148197). Hillsdale, NJ: Lawrence Erlbaum Associates Inc.

Morrison, C.M., Chappell, T.D., \& Ellis, A.W. (1997). Age of acquisition norms for a large set of object names and their relation to adult estimates and other variables. Quarterly Journal of Experimental Psychology, 50 A, 528-559.

Morrison, C.M., \& Ellis, A.W. (1995). Roles of word frequency and age of acquisition in word naming and lexical decision. Journal of Experimental Psychology: Learning, Memory, and Cognition, 21, 116-133.

Morrison, C.M., Ellis, A.W., \& Quinlan P.T. (1992). Age of acquisition, not word frequency, affects object naming, not object recognition. Memory and Cognition, 20, 705714.

Perfetti, C.A., \& Bell, L. (1991). Phonemic activation during the first $40 \mathrm{~ms}$ of word identification: Evidence from backward masking and masked priming. Journal of Memory and Language, 30, 473-485.

Rubin, D.C. (1980). 51 properties of 125 words: A unit analysis of verbal behavior. Journal of Verbal Learning and Verbal Behavior, 19, 736-755.

Segui, J., \& Grainger, J. (1990). Priming word recognition with orthographic neighbors: Effects of relative prime-target frequency. Journal of Experimental Psychology: Human Perception and Performance, 16, 65-76.

Seidenberg, M.S., \& McClelland, J.L. (1989). A distributed, developmental model of word recognition and naming. Psychological Review, 96, 523-568.

Snodgrass, J.G. (1984). Concepts and their surface representations. Journal of Verbal Learning and Verbal Behavior, 23, 3-22.

Strain, E., Patterson, K., \& Seidenberg, M.S. (1995). Semantic effects in single-word naming. Journal of Experimental Psychology: Learning, Memory, and Cognition, 21, 1140-1154.

Theios, J., \& Amrhein, P.C. (1989). Theoretical analysis of the cognitive processing of lexical and pictorial stimuli: Reading, naming, and visual and conceptual comparison. Psychological Review, 96, 5-24.

Van den Bosch, A., Content, A., Daelemans, W., \& De Gelder, B. (1994). Measuring the complexity of writing systems. Journal of Quantitative Linguistics, 1, 178-188.

van Loon-Vervoorn, W.A. (1985). Voorstelbaarheidswaarden van Nederlandse woorden. Lisse, The Netherlands: Swets \& Zeitlinger. 
van Loon-Vervoorn, W.A. (1989). Eigenschappen van basiswoorden. Lisse, The Netherlands: Swets \& Zeitlinger.

Whaley, C.P. (1978). Word-nonword classification time. Journal of Verbal Learning and Verbal Behavior, 17, 143-154.

\section{APPENDIX 1:}

\section{Stimuli of Experiments $1 \mathrm{a}-\mathrm{c}$}

$\operatorname{logfr}=$ logarithm (base 10) of frequency counts (on a total of $42,380,000$ )

AoA $=$ percentage of teachers indicating that a 6 -year-old should know the word

IMA $=$ imageability rating on a scale from 1 to 7

translation $=$ first translation according to the "Van Dale Handwoordenboek Nederlands-Engels"; this translation is only approximate and the meaning of the Dutch word is often more restrictive than the English translation

AoA

$\log f$ AoA IMA

gong (gong)

lakei (lackey)

ruif (rack)

keet (hut)

aard (nature)

tobbe (tub)

steeg (lane)

eeuw (century)

griet (chick)

salto (somersault)

schol (plaice)

kwark (curd cheese)

asiel (asylum)

kreng (bitch)

gulp (fly)

drama (tragedy)

pond (pound)

bink (he-man)

lont (fuse)

flap (flap)

geul (trench)

psalm (psalm)

roes (fuddle)

klier (gland)

Means

$\begin{array}{rrr}1.8 & 14 & 5.9 \\ 2.1 & 16 & 5.9 \\ 1.3 & 3 & 3.9 \\ 2.0 & 4 & 5.9 \\ 3.8 & 12 & 3.1 \\ 1.9 & 7 & 5.5 \\ 2.4 & 7 & 6.1 \\ 4.0 & 11 & 3.4 \\ 2.2 & 9 & 6.0 \\ 1.7 & 8 & 5.1 \\ 1.9 & 12 & 5.7 \\ 1.9 & 7 & 5.8 \\ 2.3 & 3 & 5.4 \\ 2.5 & 9 & 4.8 \\ 2.3 & 8 & 6.0 \\ 2.8 & 14 & 3.8 \\ 2.8 & 9 & 4.8 \\ 1.8 & 2 & 5.0 \\ 2.1 & 7 & 5.6 \\ 2.0 & 14 & 3.6 \\ 2.2 & 7 & 5.6 \\ 2.4 & 6 & 4.2 \\ 2.5 & 4 & 3.8 \\ 2.4 & 1 & 2.9 \\ 2.3 & 8 & 4.9\end{array}$

patat (chips)

prei (leek)

boor (brace)

hoest (cough)

duur (expensive)

klont (lump)

hagel (hail)

maand (month)

zalf (ointment)

slurf (trunk)

zebra (zebra)

spade (spade)

pluim (plume)

pret (fun)

taart (cake)

dief (thief)

boon (bean)

haag (hedge)

tulp (tulip)

rups (caterpillar)

kers (cherry)

fluit (flute)

koek (cake)

krijt (chalk)

Means $\log f r$ AoA IMA

$\begin{array}{lll}1.9 & 90 & 6.8\end{array}$

$\begin{array}{lll}2.2 & 91 & 6.4\end{array}$

$\begin{array}{lll}1.9 & 90 & 6.5\end{array}$

$\begin{array}{lll}2.1 & 97 & 4.7\end{array}$

$\begin{array}{lll}3.7 & 92 & 3.9\end{array}$

$\begin{array}{lll}1.9 & 90 & 5.0\end{array}$

$\begin{array}{lll}2.2 & 92 & 6.3\end{array}$

$\begin{array}{lll}4.0 & 92 & 4.3\end{array}$

$\begin{array}{lll}2.4 & 93 & 5.8\end{array}$

$\begin{array}{lll}1.8 & 90 & 6.6\end{array}$

$\begin{array}{lll}1.6 & 92 & 6.8\end{array}$

$\begin{array}{lll}1.9 & 90 & 5.6\end{array}$

$\begin{array}{lll}2.3 & 93 & 5.9\end{array}$

$\begin{array}{lll}2.5 & 91 & 5.2\end{array}$

$\begin{array}{lll}2.6 & 97 & 5.5\end{array}$

$\begin{array}{lll}2.8 & 97 & 5.9\end{array}$

$\begin{array}{lll}2.8 & 97 & 6.4\end{array}$

$\begin{array}{lll}1.9 & 91 & 5.7\end{array}$

$\begin{array}{lll}2.1 & 97 & 6.8\end{array}$

$\begin{array}{lll}2.1 & 91 & 6.4\end{array}$

$\begin{array}{lll}2.3 & 98 & 6.6\end{array}$

$\begin{array}{lll}2.4 & 96 & 6.4\end{array}$

$\begin{array}{lll}2.6 & 98 & 6.4\end{array}$

$2.4 \quad 95 \quad 6.5$

$\begin{array}{lll}2.4 & 93 & 5.9\end{array}$ 


\section{Frequency}

$\begin{array}{lccclccc} & \log f r & \text { AoA } & I M A & & \log f r & \text { AoA } & I M A \\ \text { krent (currant) } & 1.6 & 60 & 6.6 & \text { arts (doctor) } & 3.6 & 59 & 6.7 \\ \text { puree (puree) } & 1.9 & 95 & 6.0 & \text { hoofd (head) } & 4.4 & 95 & 6.4 \\ \text { friet (chips) } & 1.9 & 95 & 6.6 & \text { licht (light) } & 4.2 & 95 & 6.4 \\ \text { knook (bone) } & 1.5 & 25 & 3.9 & \text { geval (case) } & 4.4 & 37 & 2.2 \\ \text { smak (fall) } & 2.1 & 40 & 3.6 & \text { zaak (thing) } & 4.3 & 54 & 4.7 \\ \text { dooi (thaw) } & 1.6 & 69 & 3.6 & \text { kant (side) } & 4.1 & 71 & 4.8 \\ \text { netel (nettle) } & 1.5 & 74 & 4.3 & \text { enkel (single) } & 4.4 & 75 & 6.4 \\ \text { plons (splash) } & 2.0 & 76 & 4.7 & \text { vorm (form) } & 4.2 & 81 & 4.1 \\ \text { stoof (stove) } & 1.9 & 81 & 5.7 & \text { leven (life) } & 4.7 & 81 & 3.5 \\ \text { buil (bump) } & 1.9 & 88 & 5.3 & \text { stuk (piece) } & 4.1 & 87 & 4.8 \\ \text { vilt (felt) } & 1.6 & 28 & 4.4 & \text { ruim (more than) } & 3.7 & 33 & 4.1 \\ \text { gerei (gear) } & 1.0 & 45 & 4.0 & \text { grens (border) } & 3.7 & 45 & 5.5 \\ \text { judo (judo) } & 1.4 & 48 & 5.2 & \text { vlak (surface) } & 3.8 & 48 & 4.9 \\ \text { moes (puree) } & 1.8 & 49 & 5.1 & \text { taak (task) } & 3.8 & 48 & 3.4 \\ \text { ijzel (black ice) } & 1.6 & 66 & 4.7 & \text { buurt (neighbourhood) } & 3.7 & 65 & 4.9 \\ \text { prul (trash) } & 1.9 & 67 & 4.0 & \text { druk (busy) } & 3.8 & 65 & 3.9 \\ \text { vlaai (flan) } & 1.2 & 65 & 5.8 & \text { doel (target) } & 3.8 & 67 & 5.4 \\ \text { graat (fish bone) } & 1.9 & 72 & 6.0 & \text { wapen (weapon) } & 3.5 & 74 & 6.0 \\ \text { hark (rake) } & 1.8 & 81 & 6.4 & \text { angst (fear) } & 3.9 & 74 & 4.4 \\ \text { snoet (snout) } & 1.9 & 54 & 5.0 & \text { zijde (side) } & 3.5 & 53 & 5.6 \\ \text { duik (dive) } & 1.9 & 79 & 5.3 & \text { deel (part) } & 4.2 & 80 & 4.1 \\ \text { roest (rust) } & 1.9 & 79 & 5.2 & \text { soort (sort) } & 4.2 & 79 & 3.0 \\ \text { vaat (washing-up) } & 1.9 & 72 & 5.8 & \text { kans (chance) } & 3.9 & 61 & 3.7 \\ \text { noen (noon) } & 1.6 & 59 & 2.0 & \text { plan (plan) } & 3.9 & 60 & 3.3 \\ \text { Means } & 1.7 & 65 & 5.0 & \text { Means } & 4.0 & 66 & 4.7\end{array}$

\section{Imageability}

$\begin{array}{lccclccc} & \log f r & \text { AoA } & \text { IMA } & & \log f r & \text { AoA } & \text { IMA } \\ \text { zeur (bore) } & 1.4 & 29 & 3.2 & \text { jojo (yo-yo) } & 1.4 & 29 & 6.5 \\ \text { frats (antics) } & 1.7 & 18 & 2.4 & \text { kluif (knuckle) } & 1.5 & 22 & 6.1 \\ \text { gunst (favour) } & 3.0 & 18 & 2.4 & \text { kruin (crown) } & 2.6 & 24 & 5.8 \\ \text { vrees (fear) } & 3.2 & 54 & 3.5 & \text { boord (band) } & 3.3 & 54 & 6.0 \\ \text { smoes (excuse) } & 2.4 & 16 & 3.4 & \text { gaas (gauze) } & 2.4 & 19 & 6.1 \\ \text { plof (thud) } & 2.0 & 66 & 2.6 & \text { poep (crap) } & 2.1 & 65 & 6.5 \\ \text { schik (contentment) } & 2.1 & 23 & 3.1 & \text { spaak (spoke) } & 2.2 & 22 & 6.6 \\ \text { gedoe (business) } & 2.7 & 24 & 2.1 & \text { luik (hatch) } & 2.7 & 25 & 6.0 \\ \text { opzet (organisation) } & 3.2 & 37 & 3.0 & \text { spul (stuff) } & 3.1 & 37 & 6.1 \\ \text { iets (something) } & 4.7 & 91 & 2.9 & \text { mens (human being) } & 4.8 & 91 & 6.7 \\ \text { waar (where) } & 4.8 & 95 & 2.5 & \text { meer (lake) } & 4.8 & 95 & 6.4 \\ \text { ding (thing) } & 4.2 & 85 & 3.5 & \text { groep (group) } & 4.1 & 86 & 6.3 \\ \text { benul (notion) } & 2.2 & 75 & 2.1 & \text { egel (hedgehog) } & 2.1 & 74 & 6.7 \\ \text { bons (thud) } & 2.1 & 49 & 3.4 & \text { snoek (pike) } & 2.0 & 50 & 6.0 \\ \text { foef (trick) } & 2.0 & 20 & 2.2 & \text { metro (underground) } & 2.1 & 20 & 6.3 \\ \text { hekel (hackle) } & 2.9 & 18 & 2.8 & \text { tepel (nipple) } & 2.8 & 23 & 6.5\end{array}$




\section{Imageability}

$\begin{array}{lccclccc} & \log f r & \text { AoA } & \text { IMA } & & \log f r & \text { AoA } & \text { IMA } \\ \text { gemak (ease) } & 3.3 & 60 & 2.8 & \text { lijst (list) } & 3.3 & 58 & 6.1 \\ \text { stoot (thrust) } & 2.7 & 69 & 3.3 & \text { sloot (ditch) } & 2.7 & 67 & 6.5 \\ \text { vlaag (gust) } & 2.5 & 59 & 3.1 & \text { halte (stop) } & 2.4 & 59 & 6.3 \\ \text { lust (desire) } & 3.0 & 61 & 3.4 & \text { heup (hip) } & 3.0 & 67 & 6.4 \\ \text { trouw (faithful) } & 3.4 & 82 & 3.2 & \text { leger (army) } & 3.5 & 82 & 6.0 \\ \text { beurt (turn) } & 3.5 & 85 & 2.9 & \text { trein (train) } & 3.5 & 87 & 6.9 \\ \text { toer (trip) } & 2.6 & 72 & 3.1 & \text { klauw (claw) } & 2.6 & 71 & 6.3 \\ \text { vers (fresh) } & 3.4 & 91 & 2.9 & \text { veld (field) } & 3.4 & 90 & 6.1 \\ \text { Means } & 2.9 & 54 & 2.9 & \text { Means } & 2.8 & 55 & 6.3\end{array}$




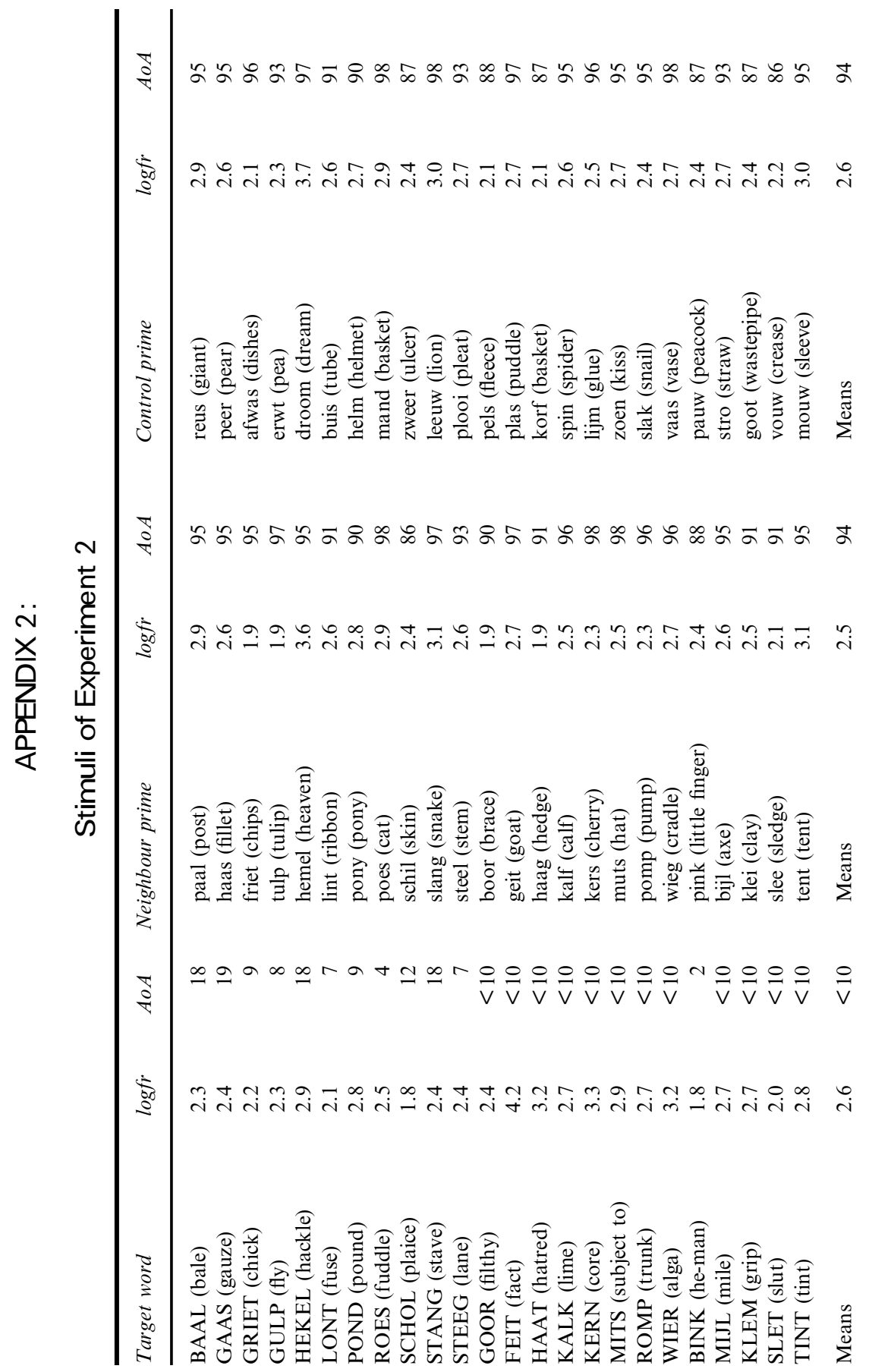




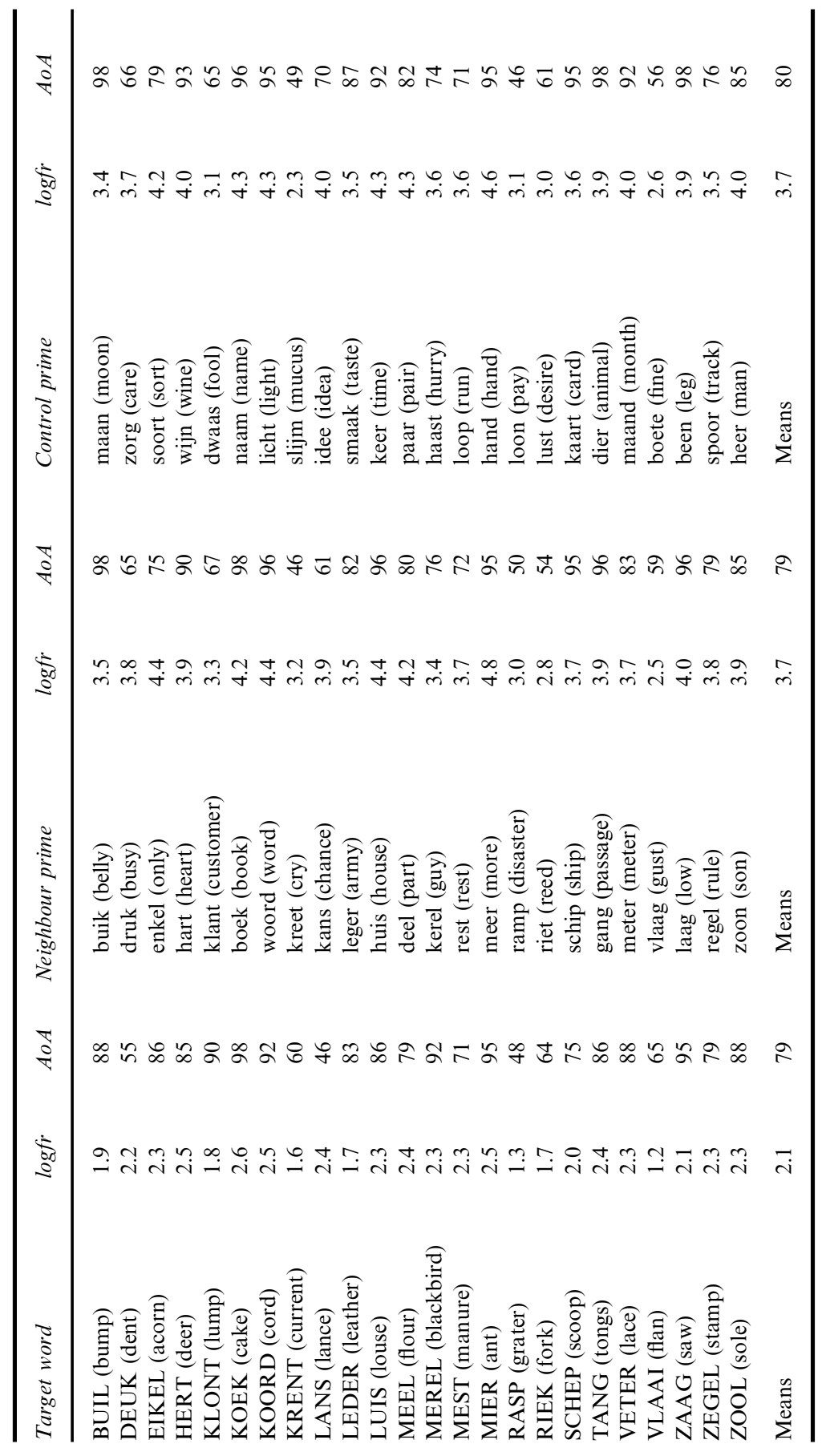

